\title{
Avaliação de diferentes pontas e volumes de pulverização na aplicação de fungicida na cultura do milho
}

\author{
Fernando Cezar Juliatti ${ }^{1}$, Cleyton Nascimento ${ }^{11}$, Anakely Alves Rezende ${ }^{1}$.
}

\author{
${ }^{1}$ Laboratório de Micologia e Proteção de Plantas, UFU, Universidade Federal de Uberlândia, Av. Amazonas, s.nº, Umuarama, C.Postal 593, CEP: \\ 38400-902, Uberlândia, MG, Brasil. \\ Autor para correspondência: Fernando Cezar Juliatti (juliatti@ufu.br)
}

Data de chegada: 21/10/2009. Aceito para publicação em: 03/08/2010.

1681

\section{RESUMO}

Juliatti, F.C.; Nascimento, C.; Rezende, A.A.. Avaliação de diferentes pontas e volumes de pulverização na aplicação de fungicida na cultura do milho. Summa Phytopathologica, v.36, n.3, p.216-221, 2010.

\begin{abstract}
A tecnologia de aplicação é um dos principais fatores para o sucesso das lavouras, pois dela depende a aplicação correta dos defensivos químicos. O experimento foi realizado na Fazenda Mandaguari (Indianópolis-MG). O delineamento experimental foi de blocos casualizados com 13 tratamentos e 4 repetições. Os tratamentos utilizados foram 4 pontas (TT, AD/D, ADIA/D, Cone Vazio) e 3 volumes de calda $\left(100,150\right.$ e $\left.200 \mathrm{~L} \mathrm{ha}^{-1}\right)$ além da testemunha. $\mathrm{O}$ objetivo do trabalho foi desenvolver o estudo de pontas de aplicação e volume adequado para o controle racional das doenças na cultura do milho. Avaliou-se a severidade das doenças, gotas $\mathrm{cm}^{-2}$, \%área verde, massa de 1000 grãos e produtividade, sendo realizada nesta uma análise
\end{abstract}

econômica. Em relação à Mancha de estenocarpela, todos os tratamentos se mostraram superior à testemunha. A ponta ADIA obteve a menor quantidade de gotas $\mathrm{cm}^{-2}$ no baixeiro da planta. Todos os tratamentos foram superiores à testemunha em relação à \%área verde. Todos os tratamentos proporcionaram um aumento no peso de 1000 grãos em relação à área não tratada, mostrando a relação direta no controle das doenças com o enchimento de grãos. A maior produtividade obtida ocorreu quando foi utilizado o volume de $100 \mathrm{~L}$ $\mathrm{ha}^{-1} \mathrm{em}$ todas as pontas avaliadas. A análise econômica demonstrou a viabilidade de uma aplicação de fungicida para garantia da sustentabilidade na produção de milho.

Palavras-chave adicionais: Zea mays, Controle químico, Tecnologia de aplicação.

\section{ABSTRACT}

Juliatti, F.C.; Nascimento, C.; Rezende, A.A.. Evaluation of different nozzles and volumes in fungicide application on maIze crop. Summa Phytopathologica, v.36, n.3, p.216-221, 2010.

Application technology is a major factor for the success of crops because it determines the correct application of pesticides. The experiment was carried out in Mandaguari Farm (Indianópolis Municipality, Minas Gerais State, Brazil). The experimental design was in randomized blocks, with 13 treatments and 4 replicates. Treatments consisted of 4 nozzles (TT, AD / D, ADIA / D, empty cone) and 3 spray mix volumes (100, 150 and $\left.200 \mathrm{~L} \mathrm{ha}^{-1}\right)$, besides control. The aim of this work was to study nozzles and to set the suitable volume of fungicide application for the rational disease management in maize crop. Disease severity, drops $\mathrm{cm}^{-2}$, green area percentage, 1000-grain weight, and yield were evaluated; an economic analysis was done for the latter. As regards leaf spot caused by fungi of the genus Stenocarpella, all treatments were superior to the control. The nozzle ADIA received the smallest quantity of drops $\mathrm{cm}^{-2}$ in the plant bottom. All treatments were superior to the control regarding green area percentage. All treatments led to increased 1000-grain weight relative to control showing the direct relationship between disease control and grain filling. The highest yield was obtained when $100 \mathrm{~L} \mathrm{ha}^{-1}$ was used in all evaluated nozzles. The economic analysis demonstrated the feasibility of fungicide application to ensure sustainability in maize production.

Keywords: Zea mays, Chemical control, Application technology.

A cultura do milho, no Brasil, está sujeita à ocorrência de várias doenças, que sob condições favoráveis, podem comprometer seriamente a qualidade e a produção de sementes e grãos. A incidência e a severidade dessas doenças têm aumentado muito, em decorrência, principalmente, de modificações no sistema de cultivo e na época de plantio do milho, bem como da expansão da área cultivada (23).

A busca por maior eficiência e redução no custo das atividades onde o uso de defensivos agrícolas é relevante, obrigaram pesquisadores e usuários a ficarem atentos para a evolução química das formulações e seus ingredientes ativos, além da eficiência dos equipamentos de pulverização, o cultivo em áreas extensivas, assim como a maior ocorrência ou incidência de novos agentes nas lavouras, por conseguinte aumentando a preocupação e policiamento em relação à contaminação do meio ambiente, levando-os assim ao manejo racional das culturas $(1,20,26)$.

O principal objetivo da aplicação de produtos fitossanitários na agricultura é o de reduzir os danos das pragas, doenças, plantas daninhas ou outros agentes prejudiciais às culturas. Quando usados de forma inadequada, esses produtos tornam se um sério risco à saúde humana e ambiental, por isso é importante reduzir as perdas na aplicação, 
aumentando-se a eficiência das operações de pulverizações $(8,21,26)$.Com avanço das doenças na cultura do milho, onde o uso de fungicidas tornou-se uma opção econômica nas pulverizações aéreas nas fases de pré e pós pendoamento $(2,6,16,17,18,19)$. Urge estudar e analisar os melhores parâmetros (pontas e volumes) para uma pulverização mais adequada tecnicamente, conforme preconiza alguns pesquisadores $(27,28,30,31)$ visando a sustentabilidade nos sistemas diferentes sistemas de produção da cultura (25).

A seleção e o uso adequado de pontas de pulverização são essenciais para a melhoria das condições de precisão e segurança na aplicação de agroquímicos $(4,8)$.Sendo fundamental para que se obtenham gotas de tamanho ideal, somado ao volume de calda aplicado formando um conjunto de fatores que devem ser considerados na tomada de decisão para o controle de doenças na cultura do milho $(5,10,17)$. Diante do exposto, urge desenvolver o estudo de pontas de aplicação e volume adequado para o controle racional das doenças na cultura do milho.

\section{MATERIAL E MÉTODOS}

O presente experimento foi conduzido na fazenda Mandaguari, no período de outubro de 2004 a abril de 2005. A altitude da propriedade é de 930 metros, e localizadas sob as coordenadas $18^{\circ} 59^{\prime} 22^{\prime \prime}$ S e $47^{\circ}$ 47' 44" WO.

A semeadura foi realizada do dia 03 de novembro de 2004, utilizando o híbrido de milho de ciclo precoce 30K75. O delineamento experimental utilizado foi o DIC (Delineamento inteiramente casualizado) com treze tratamentos e quatro repetições totalizando cinqüenta e duas parcelas. As parcelas experimentais foram compostas por "field plots" de 150 metros quadrados, compostas de 25 linhas de 6 metros de comprimento, espaçadas a quarenta e cinco centímetros entre si. A área útil das parcelas (amostragem de severidade de doenças e produção) foi constituída de duas linhas de cinco metros.
A aplicação do fungicida foi realizada no dia 08/01/2005, quando os híbridos estavam com aproximadamente $20 \%$ do florescimento masculino, ou seja, emissão do pendão. $\mathrm{O}$ produto utilizado foi o (azoxystrobina $-200 \mathrm{gL}^{-1}+$ ciproconazole $-80 \mathrm{gL}^{-1}$ ) + Nimbus, respectivamente nas doses de $0,3 \mathrm{~L} \mathrm{ha}^{-1}$ e $0,6 \mathrm{~L} \mathrm{ha}^{-1}$ do produto comercial (60 gha ${ }^{-1}$ de azoxystrobina +24 g.ha $^{-1}$ de ciproconazole). Para as pulverizações, foi utilizado o pulverizador autopropelido de marca Jacto, modelo Uniport com 23 metros de barra, dotado de um controlador eletrônico de pulverização. Conferido anteriormente aos testes por meio da determinação da velocidade de deslocamento e vazão das pontas de pulverização. A altura da barra em relação à cultura e o espaçamento entre pontas foram de $0,5 \mathrm{~m}$. A pressão empregada foi de aproximadamente $340 \mathrm{kPa}$ para as pontas de jato plano e $750 \mathrm{kPa}$, para as pontas de jato cônico e vazio. O controlador realiza automaticamente pequenas variações na pressão para compensar oscilações ocorridas na velocidade. As pontas de pulverização hidráulicas utilizadas foram (tabela 02): TT 110-02 ( jato plano defletor), MAG 02 (jato cônico vazio),AD/D 110-02 (jato plano duplo), e AD-IA/D 110-02 (jato plano duplo com indução de ar). A velocidade de deslocamento do pulverizador foi de 5, 7,5 e 10 $\mathrm{Km} \cdot \mathrm{h}^{-1}$, respectivamente para os volumes de 200, 150 e 100 L.ha $^{-1}$. Durante as aplicações foram monitoradas a temperatura, umidade relativa e a velocidade do vento.

Foram realizadas as seguintes avaliações severidade de doenças, gotas. $\mathrm{cm}^{2}$, área verde, peso de mil grãos (g) e produtividade, aseveridade das doenças (\%): Avaliaram-se as manchas foliares (mancha branca e de estenocarpela) utilizando a metodologia de área foliar doente (porcentagem visual de 0 a $100 \%$, por dois avaliadores) realizadas em três avaliações. A primeira avaliação foi realizada aos 60 dias após a emergência (D.A.E), a segunda aos 87 (D.A.E) e a terceira aos 103 (D.A.E). Foram avaliadas por repetição 5 folhas inseridas na base da espiga; b- Gotas por $\mathbf{c m}^{2}$ : Para avaliar a densidade de gotas por unidade ou superfície de área com cobertura foi realizada a contagem das gotas nos papéis hidrossensíveis (76 X $26 \mathrm{~mm})$, conforme as

Tabela 1. Característica das pontas utilizadas no experimento. UFU, Uberlândia, 2007.

\begin{tabular}{llll}
\hline Ponta & Classe de Gotas & Deriva & PRD* \\
\hline Cone Vazio MAG02 & Muita fina - Fina & Alta - Média & MF $=>57 \% \mathrm{~F}=20-57 \%$ \\
TT 11002 & Fina - Média & Média - Baixa & $\mathrm{F}=20-57 \% \mathrm{M}=5,7-20 \%$ \\
AD 11002 & Fina - Média & Média - Baixa & $\mathrm{F}=20-57 \% \mathrm{M}=5,7-20 \%$ \\
ADIA 11002 & Grossa - Muito grossa & Muito baixa & $\mathrm{G}=2,9-5,7 \% \mathrm{MG}=<2,9 \%$ \\
\hline
\end{tabular}

* O potencial de risco de deriva baseia-se na classe de gotas que gera um risco de deriva (Cunha, 2003)

Tabela 2. Análise de variância para severidade de mancha de estenocarpela (SMS) e mancha branca (SMB) aos 28 e 42 dias após a aplicação do fungicida e área abaixo da curva para manchas de estenocarpela e branca (AACPDMS e AACPDMB). UFU, Uberlândia, 2007.

\begin{tabular}{|c|c|c|c|c|c|c|c|}
\hline $\mathrm{CV}^{1}$ & G.L. ${ }^{2}$ & Q.M. ${ }^{3}$ & Q.M. ${ }^{4}$ & Q.M. ${ }^{5}$ & Q.M. ${ }^{6}$ & Q.M. ${ }^{7}$ & Q.M. ${ }^{8}$ \\
\hline Tratamento & 12 & $73,349^{* *}$ & $43,961^{\mathrm{ns}}$ & $42,738^{\mathrm{ns}}$ & $118,098^{\mathrm{ns}}$ & $8516,736^{* *}$ & $9871,123^{\mathrm{ns}}$ \\
\hline Repetição & 4 & $11,698^{\mathrm{ns}}$ & $11,639^{\mathrm{ns}}$ & $26,988^{\mathrm{ns}}$ & $60,493^{\mathrm{ns}}$ & $160,464^{\mathrm{ns}}$ & $2736,963^{\mathrm{ns}}$ \\
\hline Erro & 48 & & & & & & \\
\hline Total & 64 & & & & & & \\
\hline $\mathrm{CV}(\%)^{9}$ & 43,63 & 78,74 & 43,63 & 47,41 & 49,19 & 22 & 20 \\
\hline
\end{tabular}

${ }^{1}$ Causas da variação $\quad{ }^{2}$ Graus de liberdade ${ }^{3}$ Quadrado médio (SMS - 28 dias) ${ }^{4}$ SMS - 42 dias

${ }^{5} \mathrm{SMB}-28$ dias ${ }^{6} \mathrm{SMB}-42$ dias $\quad{ }^{7}$ AACPDMS ${ }^{8}$ AACPDMB $\quad{ }^{9}$ Coeficiente de variação

** Significativo ao nível de $1 \%$ de probabilidade pelo teste de $\mathrm{F}$ e ns (não significativo) 
recomendações de Halley et al. 2008. que foram colocados na hora da aplicação nos três terços da planta: inferior, médio e superior. A contagem seguiu o procedimento de $1 \mathrm{~cm}^{2}$ por repetição de cada tratamento; c-Área verde: Foi coletada a $1^{\text {a }}$ folha abaixo da espiga, sendo 5 folhas por tratamento, totalizando 5 repetições. Os resultados foram gerados em porcentagem descontando a porcentagem de área doente pelos diferentes patossistemas. A avaliação foi realizada 103 dias após a emergência da cultura; dProdutividade: Foram colhidas 4 repetições por tratamento numa área útil de $4,5 \mathrm{~m}^{2}$ por repetição corrigindo a umidade para $13 \%$, e extrapolando o resultado para sacas por hectare e c- Massa (g) de 1000 grãos: Foram realizadas 8 repetições de 100 sementes por repetição de cada tratamento, totalizando 4 repetições por tratamento, e depois feito a média do resultado (RAS, 2002), convergindo o peso para $13 \%$ de umidade (b.u.) dos grãos.

Para todas as variáveis foi usado o esquema de análise inteiramente ao acaso considerando a combinação de pontas e volumes como tratamentos independentes. Para a deposição de gotas. $\mathrm{cm}^{-2}$ foi considerado o esquema de análise fatorial (pontas Fator 1 e volumes -Fator 2).Foram realizadas análises de variância e testes de médias pelo software Sisvar da UFLA para todas as variáveis estudadas. A evolução da doença foi estimada através da

Tabela 3. Médias de severidade de mancha de estenocarpela ( \% SMS) aos 28 dias após da aplicação dos fungicidas e área abaixo da curva de progresso para mancha de stenocarpela (AACPDMS). UFU, Uberlândia, 2007.

\begin{tabular}{lll}
\hline Tratamento & \% SMS & AACPDMS \\
\hline Testemunha & $15,94 \mathrm{~b}$ & $200,20 \mathrm{a}$ \\
TT - 100 L ha & $4,86 \mathrm{ab}$ & $83,02 \mathrm{~b}$ \\
TT - 150 L ha & $4,68 \mathrm{ab}$ & $95,76 \mathrm{ab}$ \\
TT - 200 L ha & $2,46 \mathrm{a}$ & $64,26 \mathrm{~b}$ \\
ADIA/D - 100 L ha & $8,00 \mathrm{ab}$ & $112,14 \mathrm{ab}$ \\
ADIA/D - 150 L ha & $10,32 \mathrm{ab}$ & $163,24 \mathrm{ab}$ \\
ADIA/D - 200 L ha & $9,32 \mathrm{ab}$ & $158,62 \mathrm{ab}$ \\
AD/D - 100 L ha & $8,32 \mathrm{ab}$ & $163,24 \mathrm{ab}$ \\
AD/D - 150 L ha & $2,32 \mathrm{a}$ & $110,46 \mathrm{ab}$ \\
AD/D - 200 L ha & $4,92 \mathrm{ab}$ & $106,82 \mathrm{ab}$ \\
Cone Vazio - 100 L ha & $4,26 \mathrm{a}$ & $93,80 \mathrm{ab}$ \\
Cone Vazio - 150 L ha & $3,66 \mathrm{a}$ & $79,24 \mathrm{~b}$ \\
Cone Vazio - 200 L ha & $5,48 \mathrm{ab}$ & $85,54 \mathrm{~b}$ \\
\hline
\end{tabular}

Médias seguidas por letras distintas se diferem entre si pelo teste de Tukey ao nível de significância de $5 \%$. área abaixo da curva de progresso da doença (AACPD), utilizando os dados de severidade (\%), conforme (7), com base nos dados de avaliação das doenças. Analisou-se o teste de comparação de médias Tukey a 5\% para as variáveis produtividade, massa de 1000 grãos, gotas por $\mathrm{cm}^{2}$, área verde e área abaixo da curva de progresso da doença. Foi realizada a análise econômica para a utilização das diferentes pontas versus os volumes de calda na aplicação de fungicidas na cultura do milho.

\section{RESULTADOS E DISCUSSÃO}

Os dados climáticos durante a apliocação foram: temperatura $=$ $26,7^{\circ} \mathrm{C}$; umidade $=75 \%$, velocidade do vento $=2,8 \mathrm{~km} \mathrm{~h}^{-1}$ ).

$\mathrm{Na}$ avaliação da severidade das doenças foliares (mancha de estenocarpela e mancha branca) encontrou-se diferenças significativas entre as combinações de pontas e volumes apenas para mancha de Stenocarpella ou Diplodia macrospora. Tanto na avaliação aos 28 dias quanto para a área abaixo da curva de progresso da doença (AACPD) (tabela 2). Esses resultados estão de acordo com os obtidos (13) que demonstraram a evolução da doença no cerrado brasileiro, justificando o uso do controle químico, uma vez que a resistência genética à doença ainda não foi devidamente pesquisada. Resultados semelhantes foram encontrados por $(6,32)$, para os patossistemas mancha branca e ferrugem comum do milho. Esta resposta variada depende do genótipo usado, ano agrícola e época de plantio $(10,17)$. Em relação as pontas utilizadas e os respectivos volumes se destacaram no controle da doença as pontas: TT-110-02 no volume de 100 e 200 l.ha ${ }^{-1}, \mathrm{AD} / \mathrm{D}$ - 150 L.ha $^{-1}$ e Cone vazio nos volumes de 100 e 150 L.ha $^{-1}$. As demais pontas e volumes apresentaram um comportamento intermediário e foram superiores à testemunha (tabela 3). Quanto a deposição de gotas. $\mathrm{cm}^{-2}$ nota-se que pela tabela 4 , esta foi significativa apenas nas folhas do terço inferior (tabela 4). Não havendo interação de ponta $X$ volume. A maior deposição de gotas ocorreu com a ponta cone vazio que foi superior às demais. A menor deposição foi com a ponta com indução de ar (ADIA). Resultados obtidos em soja $(9,11,12)$ demonstram que as pontas de jato cônico estão sujeitas a deriva. Para (22) a aplicação realizada no horário das 14:00h com a ponta jato plano defletor, as plantas desenvolveram maior número de lesões e urédias de ferrugem da soja no terço médio, quando comparada as pontas jato plano defletor duplo e jato plano duplo. Conforme (9) o potencial de risco de deriva baseia-se na classe de gotas que gera um risco de deriva, ou seja, é a distância que as gotas podem ser arrastadas quando liberadas de determinada altura, em função do tamanho das gotas pulverizadas, da densidade do líquido e da velocidade horizontal.

Tabela 4. Análise de variância para gotas.cm ${ }^{-2}$ no terço superior, médio e inferior da planta. UFU, Uberlândia, 2007.

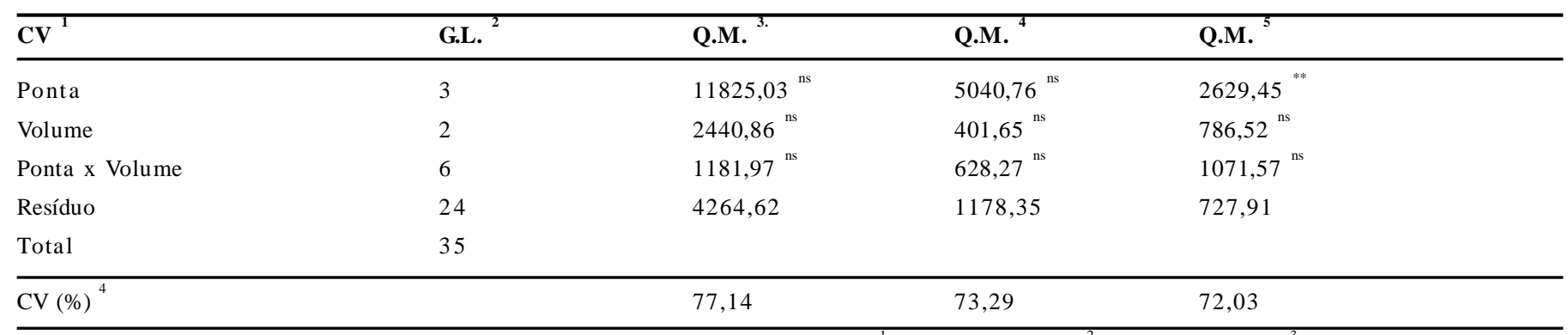

** Significativo ao nível de $1 \%$ de probabilidade pelo teste de F e ns (não significativo); ${ }_{5}^{1}$ Causas da variação; ${ }^{2}$ Graus de liberdade; ${ }^{3}$ Quadrado médio nas folhas do terço superior; ${ }^{4}$ Quadrado médio nas folhas do terço médio; ${ }^{5}$ Quadrado médio nas folhas do terço inferior; ${ }^{4}$ Coeficiente de variação 
Tabela 5. Número médio de gotas depositadas $\left(\right.$ gotas. $\left.\mathrm{cm}^{-2}\right)$, nas folhas do terço inferior de plantas de milho. UFU,Uberlândia, 2007.

\begin{tabular}{ll}
\hline Ponta & Médias \\
\hline CONE VAZIO MAG02 & $56,33 \mathrm{a}$ \\
T T & $47,38 \mathrm{ab}$ \\
AD & $24,88 \mathrm{ab}$ \\
ADIA & $21,22 \mathrm{~b}$ \\
\hline
\end{tabular}

Médias seguidas por letras distintas na vertical diferem entre si pelo teste de Tukey ao nível de significância de $5 \%$.

No controle da ferrugem da soja as aplicações realizadas utilizando a ponta jato plano duplo proporcionaram menor número de urédias no terço inferior da cultura, da soja quando comparou-se a ponta jato plano de uso ampliado (22). As gotas produzidas por uma ponta (bico) são classificadas como muito finas, finas, médias, grossas e muito grossas. (24) afirmam que o número de gotas. $\mathrm{cm}^{-2}$ de folha é determinante na efetividade biológica do tratamento, sendo necessário o mínimo de 30 a 40 gotas $/ \mathrm{cm}^{2}$, as quais devem apresentar o diâmetro mediando volumétrico entre 101 e $300 \mu \mathrm{m}$ (gotas pequenas a médias). Presume-se que a ponta cone vazio depositou maior gotas nas folhas do baixeiro devido as gotas mais finas ou de menor volume, o que permite um maior arraste lateral pelo vento, podendo inclusive escaparem do alvo.

Para $(9,15)$ o aumento do volume propiciou o aumento da deposição de gotas em plantas de milho utilizando as mesmas pontas do presente trabalho. Para os autores de maneira geral a maior deposição ocorreu com as pontas jato plano defletor, no volume de calda de 130 L.ha- ${ }^{-1}$. A ponta com indução de ar mostrouse inadequada para aplicação de fungicida, em virtude dos baixos valores de densidade de gotas encontrados. No presente trabalho as pontas AD e ADIA apresentaram uma deposição média de 25 e 21 gotas. $\mathrm{cm}^{-2}$, abaixo dos valores estipulados por (16 ). Para (3) a cultura do milho permite uma maior cobertura ao bico plano de menor vazão (110-SF-01) e também uma maior deposição de gotas na entrelinha, não influenciando a deposição de gotas mesmo quando era alterada a altura de coleta. (29) também demonstraram as vantagens associadas ao uso de gotas de menores diâmetros na aplicação de agroquímicos.

A área verde representa a porcentagem de área foliar que está fotossinteticamente ativa sem a presença de doenças ou dano por pragas. Quanto maior a área verde, maior é o acúmulo de fotoassimilados que serão destinados ao enchimento de grãos. Houve variação nos resultados da \% área verde, mostrando que as pontas versus volume interferem na eficácia da aplicação (Tabela 6 e 7). Esta variável tem sido analisada e observada nas aplicações com as misturas de triazóis e estrobilurinas na cultura do milho (17), com melhoria no rendimento da cultura em locais com pressão moderada a alta severidade das doenças foliares na cultura.Considerando que no Brasil os patossistemas são múltiplos $(2,6,17)$ esta ferramenta poderá ser muito útil em futuros trabalhos, desde que corretamente avaliada, por escalas diagramáticas e/ou equipamentos como o Spad que medem o índice de clorofilas a e b.

Observou-se que houve efeito das pontas e volumes no peso de 1000 grãos de milho, sendo importante ressaltar que o coeficiente de variação foi de $4,91 \%$. O volume de $100 \mathrm{~L} \mathrm{ha}^{-1}$ obteve um peso de 1000 grãos superior aos demais volumes utilizados em todas as pontas avaliadas. A maior produtividade foi obtida com a ponta TT no volume de $100 \mathrm{~L} \mathrm{ha}^{-1}$ com 171,6 sc ha-1, o qual foi o único tratamento que diferiu estatisticamente da testemunha. Podemos

Tabela 6. Análise de variância para porcentagem de área verde (PAV), peso de mil grãos (g)(PMG) e produtividade.ha ${ }^{-1}$. (P) UFU, Uberlândia, 2007.

\begin{tabular}{|c|c|c|c|c|}
\hline $\mathrm{CV}^{1}$ & G.L. ${ }^{2}$ & Q.M.A.V. $^{3}$ & Q.M.P.M.G. $^{4}$ & Q.M.P ${ }^{5}$ \\
\hline Tratamento & 12 & $217,246^{* *}$ & $638,44^{* *}$ & $379,854^{* * *}$ \\
\hline Repetição & 4 & $101,712^{\mathrm{ns}}$ & $102,403^{\mathrm{ns}}$ & $76,395^{\mathrm{ns}}$ \\
\hline Erro & 48 & & & \\
\hline Total & 64 & & & \\
\hline $\mathrm{CV}(\%)^{9}$ & 43,63 & 15,43 & 4,91 & 8,52 \\
\hline
\end{tabular}

${ }^{1}$ Causas da variação; ${ }^{2}$ Graus de liberdade; ${ }^{3}$ Quadrado médio $\mathrm{AV} ;{ }^{4} \mathrm{PMG} ;{ }^{5} \mathrm{P}{ }^{6}$ Coeficiente de variação; ** Significativo ao nível de $1 \%$ de probabilidade pelo teste de $\mathrm{F}$ e ns (não significativo)

Tabela 7. Percentagem de área verde (\%), peso de mil grãos (g) e produtividade em sc ha ${ }^{-1}$ para as diferentes pontas e volumes. UFU, Uberlândia, 2007.

\begin{tabular}{|c|c|c|c|}
\hline Tratamento & Porcentagem de área verde $(\%)$ & Peso de 1000 grãos (g) & Produtividade (sc ha ${ }^{-1}$ ) \\
\hline Testemunha & $40,32 \mathrm{~b}$ & $280,35 \mathrm{~b}$ & $136,3 \mathrm{~b}$ \\
\hline $\mathrm{TT}-100 \mathrm{~L} \mathrm{ha}^{-1}$ & $63,34 \mathrm{a}$ & $321,25 \mathrm{a}$ & $171,6 \mathrm{a}$ \\
\hline $\mathrm{TT}-150 \mathrm{~L}$ ha & $59,66 \mathrm{ab}$ & $304,20 \mathrm{ab}$ & $153,2 \mathrm{ab}$ \\
\hline $\mathrm{TT}-200 \mathrm{~L}$ ha & 64,66 a & $317,45 \mathrm{ab}$ & $152,5 \mathrm{ab}$ \\
\hline ADIA/D - $100 \mathrm{~L}$ ha & $56,66 \mathrm{ab}$ & $314,35 \mathrm{ab}$ & $153,0 \mathrm{ab}$ \\
\hline ADIA/D - $150 \mathrm{~L}$ ha & $54,00 \mathrm{ab}$ & $295,25 \mathrm{ab}$ & $142,8 \mathrm{ab}$ \\
\hline ADIA/D - $200 \mathrm{~L}$ ha & $58,00 \mathrm{ab}$ & $302,85 \mathrm{ab}$ & $145,1 \mathrm{ab}$ \\
\hline $\mathrm{AD} / \mathrm{D}-100 \mathrm{~L}$ ha & $60,32 \mathrm{a}$ & $322,90 \mathrm{a}$ & $167,1 \mathrm{ab}$ \\
\hline $\mathrm{AD} / \mathrm{D}-150 \mathrm{~L}$ ha & $60,32 \mathrm{a}$ & $310,30 \mathrm{ab}$ & $146,7 \mathrm{ab}$ \\
\hline $\mathrm{AD} / \mathrm{D}-200 \mathrm{~L}$ ha & $56,00 \mathrm{ab}$ & $298,25 \mathrm{ab}$ & $145,8 \mathrm{ab}$ \\
\hline Cone Vazio - $100 \mathrm{~L}$ ha & $67,32 \mathrm{a}$ & $325,60 \mathrm{a}$ & $157,6 \mathrm{ab}$ \\
\hline Cone Vazio $-150 \mathrm{~L}$ ha & $54,66 \mathrm{ab}$ & $311,30 \mathrm{ab}$ & $155,7 \mathrm{ab}$ \\
\hline
\end{tabular}


observar que para todas as pontas utilizadas o melhor volume foi o de $100 \mathrm{~L} \mathrm{ha}^{-1}$. Infere-se que no volume de $100 \mathrm{~L}$, independente da ponta concentra-se o i. a. do fungicida permitindo um melhor potencial de controle das manchas foliares do milho corroborando para melhor manutenção da área verde o que reflete no peso de mil grãos (g) e na produtividade. (10) não encontraram diferenças entre pontas semelhantes às utilizadas no presente trabalho em relação ao peso da massa de grãos (PMG) e produtividade. Os autores trabalharam com volumes de 70, 100 e 130 L.ha $^{-1}$. No presente trabalho o volume de aplicação para as mesmas pontas variou de 100,150 e $200 \mathrm{~L}$. Os autores atribuíram as variações de clima que não permitiram verificar esta resposta e ou o potencial de inóculo baixo das doenças, naquela condição de experimentação que não permitiram verificar as diferenças entre pontas e volumes. Os resultados encontrados concordam com o trabalho de (4). Os autores obtiveram resultados semelhantes de produtividade de soja aplicando fungicida sistêmico para o controle de oídio (Microsphaera diffusa Cooke \& Peck), com diferentes pontas, indicando haver possibilidade de se dar preferência àquelas com menor risco de deriva.Devido ao maior índice de área foliar da soja comparado ao do milho presume-se na possibilidade de se usar volumes de aplicação menores para a cultura do milho.Para (9) devido a agressividade da doença no baixeiro do dossel é necessário desenvolver estratégias de deposição para o controle da ferrugem da soja.Enquanto que no milho a menor evolução e a agressividade das doenças (17), permitem uma melhor flexibilidade no sistema de deposição, dado a menor agressividade das doenças incidentes quando comparadas à ferrugem da soja.

$\mathrm{Na}$ análise econômica vislumbra-se que a utilização de fungicidas em função da tecnologia de aplicação com a ponta TT no volume $100 \mathrm{~L} \mathrm{ha}^{-1}$ apresentou o maior retorno econômico (Tabelas 8 e 9). Seguida pela ponta AD no mesmo volume. Este resultado demonstra

Tabela 8. Análise do custo de aplicação do fungicida por hectare

\begin{tabular}{llll}
\hline Variação & Preço R $\mathbf{( L i t r o )}$ & Dose $\left(\mathbf{L ~ h a ~}^{-1}\right)$ & Custo $\mathbf{R} \mathbf{\text { ha }}{ }^{-1}$ \\
\hline Priori Xtra & 190,00 & 0,3 & 57,00 \\
Operacional & -- & -- & 11,00 \\
\hline Total & & 68,00 \\
\hline *Cotação em 13/06/2005 & &
\end{tabular}

que se pode reduzir o volume de aplicação em milho conforme a ponta utilizada. É importante frisar que este resultado pode ser variável em função do híbrido utilizado ou ainda do espaçamento da cultura, o que não foi objetivo do presente trabalho (16). Esta ferramenta se mostra de grande importância na tomada de decisão, tanto para os produtores, quanto para técnicos e profissionais da extensão que trabalham diretamente nestas funções.

A despeito da complexidade da interação entre estes fatores, a pesquisa tem mostrado a viabilidade de utilização de volumes de pulverização próximos a $100 \mathrm{~L} \mathrm{ha}^{-1}$ com pontas de jato plano defletor, em várias situações, para certas culturas como o milho (10).

\section{CONCLUSÕES}

1- Para mancha de estenocarpela as melhores pontas utilizadas foram TT e Cone vazio obtendo as menores \% severidade para a Área abaixo da curva de progresso da doença.

2-A menor \% de área verde foi resultante do tratamento testemunha.

3- A ponta ADIA/D foi a que apresentou menor quantidade de gotas $\mathrm{cm}^{-2}$ no baixeiro da planta.

4- O melhor volume utilizado foi o de $100 \mathrm{~L} \mathrm{ha}^{-1}$, obtendo uma média de produtividade de $162,3 \mathrm{sc} \mathrm{ha}^{-1}$, devido ao maior efeito de concentração do ingrediente ativo na calda de aplicação e ao menor escorrimento superficial na folha.

5- Houve diferença significativa para a ponta TT no volume de $100 \mathrm{~L} \mathrm{ha}^{-1}$ para produtividade.

6- $\mathrm{O}$ volume de $100 \mathrm{~L} \mathrm{ha}^{-1}$ se mostrou superior à testemunha para o peso de 1000 grãos.

7- Quando se usa o volume de $100 \mathrm{~L} \mathrm{ha}^{-1}$ e pontas TT e AD/D obteve-se maior retorno econômico.

\section{AGRADECIMENTOS:}

Ao Clube dos Amigos da Terra de Uberlândia pelo apoio na condução do presente trabalho.

Tabela 9. Análise econômica para volumes e pontas de aplicação em relação à área não tratada.UFU, Uberlândia, 2007.

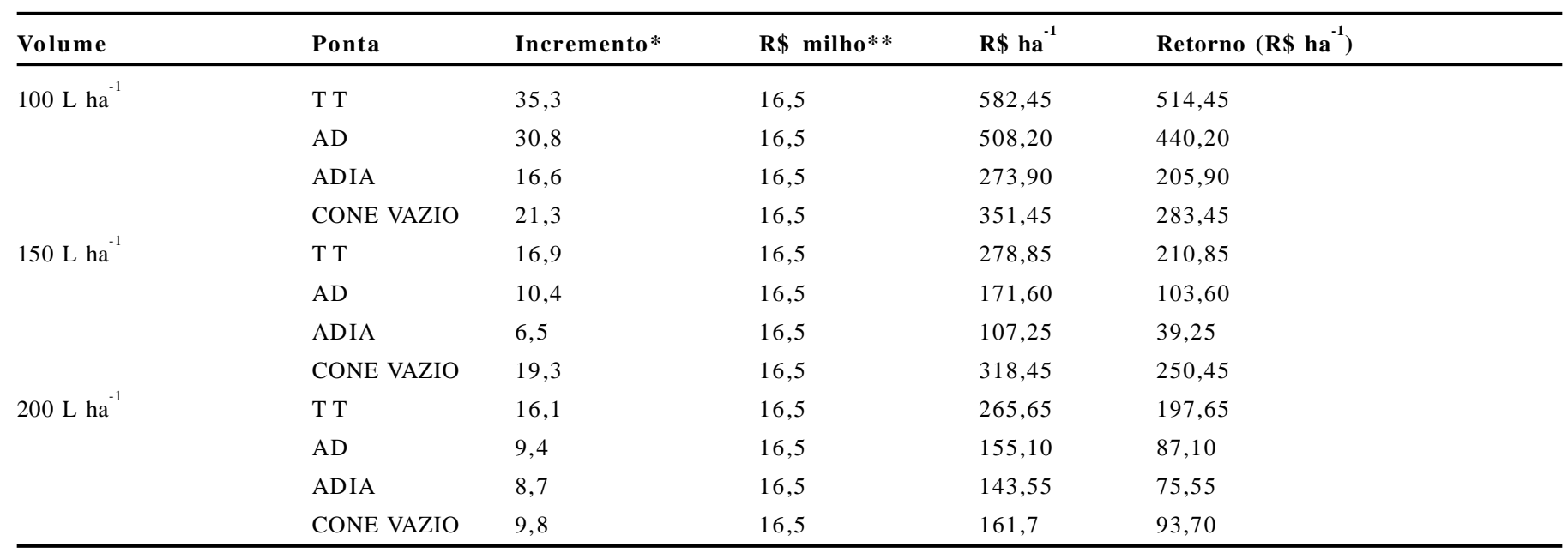

\footnotetext{
** Saca de 60 kg sendo a cotação realizada dia 13/06/2005 na Bolsa de Mercadorias de Uberlândia. * Incremento em sacas por hectare em relação a testemunha
} 


\section{REFERÊNCIAS BIBLIOGRÁFICAS}

1. Antuniassi, U.R., Camargo, T.V., Bonelli, A.P.O., Romagnole, H.W.C. Avaliação da cobertura de folhas de soja em aplicações terrestre com diferentes tipos de pontas. In: III Simpósio Internacional de Tecnologia de Aplicação de Agrotóxicos, 3., 2004, Botucatu, SP. Anais ... Botucatu: FEPAF, 2004. p.48-51.

2. Appelt, C.C.S. Manejo da feosféria, ferrrugem comum do milho e da cercosporiose pelo uso da resistência genética e épocas de aplicação. 2002. 76p. Dissertação ( Mestrado em Fitopatologia) - ICIAG,UFU, Uberlândia.

3. Berni, R.F.; Machado, V.O.F.; Costa, G.R.; Barata, G.; Paula, R.S. de. Avaliação da cobertura de gotas provocada por diferentes bicos de pulverização na cultura do milho e do feijão. Disponível em: <http://www.revistas.ufg.br/index.php/pat/article/ viewFile/2877/2933>. Acesso: 17 set. 2009.

4. Boller, W.; Forcelini, C.A.; Braun, E. Efeitos da utilização de diferentes pontas de pulverização no controle químico de oídio em soja. In: Reunião de Pesquisa de soja da REGIÃO SUL, 30. 2002, Cruz Alta. Anais... Cruz Alta: Fundacep-Fecotrigo, 2002. p.104.

5. Bonadiman, R. Pontas de pulverização e volumes de calda no controle de Anticarsia gemmatalis Hübner, 1818 e Piezodorus guildinii (Westwood, 1837) na cultura da soja.Santa Maira: UFSM, RS, 2008. p.18. Dissertação (Mestrado) - Universidade Federal de Santa Maria, Centro de Ciências Rurais, Programa de Pós-Graduação em Engenharia Agrícola, RS, 2008.

6. Brandão, A. M. Manejo da cercosporiose (Cercospora zeaemaydis Tehon \& Daniels) e da ferrugem comum do milho (Puccinia sorghi SCHW) pelo uso da resistência genética, fungicidas e épocas de aplicação. 2002.143p. Dissertação (Mestrado em Fitopatologia) - ICIAG, UFU, Uberlândia.

7. Campbell, C.L.; Madden, L.V. Introduction to plant disease epidemiology. New York: Jonh Wiley \& Sons, 1990. 532 p.

8. Carreira, S.M. Treinamento técnico verão 2005. Tecnologia de aplicação. Monsanto do Brasil. Santa Cruz das Palmeiras, SP; Abril 2005

9. Cunha, J.P.R. da; Moura, E.A.C.; Silva Júnior, J.L. da; Zago, F.A.; Juliatti, F,C, Efeito de pontas de pulverização no controle químico da ferrugem da soja.Engenharia Agrícola, v.28, n.2, p.283291,2008

10. Cunha, J.P.R. da; Pereira, R.G. Efeito de pontas e volume de pulverização no controle químico de doenças do milho. Revista Ciências Agronômicas, Fortaleza, v.40, n.04, p.533-538, 2009.

11. Cunha, J. P. A. R.; Reis, E. F. dos; Santos, R.O. dos. Controle químico da ferrugem asiática da soja em função de pontas de pulverização e de volumes de calda. Ciência Rural, v.36, n.5, p.1360-1366, set-out, 2006

12. Cunha, J.P.R. da; Teixeira, M.M. Escolha a dedo. Revista Cultivar Máquinas, n.18, março/abril de 2003.

13. Duarte, R. P.; Juliatti, F. C.; Freitas, P. T. Eficácia de diferentes fungicidas na cultura do milho. Biosci. J., Uberlândia, v. 25 , n. 4 , p. 101-111, July/Aug. 2009.

14. Fancelli, A.L., Dourado-Neto, D. Milho: estratégias de manejo para alta produtividade. Piracicaba. ESALQ/USP. 2003. 208p.

15. Halley, S. Fungicide deposition measurement by spray volume, drop size and sprayer system in cereal grains. Applied Engineering in Agriculture, v.24, n.01, p.15-21, 2008.

16. Hoffmann, L. L.; Boller, W. Tecnologia de aplicação de fun- gicidas em soja. In: Coodetec, Cooperativa Central de Pesquisa Agrícola.Tecnologia de aplicação de defensivos agrícolas. Cascavel: Bayer CropScience, p.46-60. 2004.

17. Juliatti, F.C.; Brandão, A.M.; Santos, J.A.S.; Luz, W.C. Fungicidas na parte aérea da cultura da cultura do milho: evolução de doenças fúngicas, perdas, resposta de híbridos, e melhoria da qualidade da produção. Revisão Anual de Patologia de Plantas, v.15, p. 277-334, 2007.

18. Juliatti, F.C.; Brandão, A. M. Cercosporiose em milho ( Cercospora zeae-maydis Tehon \& Daniels) afeta plantio em milho no cerrado brasileiro. Uberlândia, MG. ICIAG - UFU. Boletim técnico informativo, 2000. $45 \mathrm{p}$.

19. Juliatti, F.C.; Souza, R.M. Efeito de épocas de plantio na severidade de doenças foliares e produtividade de híbridos de milho. Bioscience Journal, v.21, n.01, p.103-112, 2005.

20. Juliatti, F.C.; Polizel, A.C.; Hamawaki, O.T. Workshop Brasileiro sobre a Ferrugem Asiática. Uberlândia: EDUFU, 2005. 232 p. :lb il.

21. Matuo, T. Técnica de aplicação de defensivos agrícolas Jaboticabal: Funep, 1990. 139p.

22. Nascimento, J.M.; Souza, C.M.A.; Gavassoni, W.L.; Bacchi, L.A.M.; Fengler, G.W. Controle de ferrugem asiática da soja utilizando-se diferentes pontas de pulverização em Maracaju-MS Revista Ciências Técnicas Agropecuárias, v. 18, n. 1, p.1-6, 2009

23. Oliveira, E.; Fernandes, F.T.; Casela, C.R.; Pinto, N.F.J.A.; Ferreira, A.S. Diagnose e controle de doenças na cultura do milho. In: Galvão, J.C.C.; Miranda, G.V. Tecnologias de Produção do Milho: economia, cultivares, biotecnologia, safrinha, adubação, quimigação, doenças, plantas daninhas e pragas. 4ed. Viçosa: UFV, 2004.p.227-247.

24. Palladini, L.A. Metodologia para avaliação da deposição em pulverizações. Botucatu, 2000. 111p. Tese (Doutorado em Agronomia/ Energia na Agricultura) - Faculdade de Ciências Agronômicas, Universidade Estadual Paulista.

25. Rezende, J.L. Controle de doenças no milho \& tratamento aéreo. In: http://semear.net/v1/noticia.asp?ID=1156 (Consulta em 13/07/2010).

26. Santos, J.M.F.dos. Tecnologia De Aplicação De Defensivos Agrícolas. Disponível em: < http://www.biologico.sp.gov.br/rifib/IIIRifib/109-116.pdf >. Acesso: 17 set. 2009.

27. Salyani, M. Optimization of sprayer output at different volume rates. St. Joseph: ASAE, 1999. CD ROM. (ASAE Paper n.99-1028).

28-Salyani, M.; Cromwell, R. P. Spray drift from ground and aerial applications. Transactions of the ASAE, v.35, n.4, p. 1113-1120, 1992.

29. Salyani, M.; Cromwell, R. P. Deposition efficiency of different droplet sizes for citrus spraying. Trans. ASAE, St. Joseph, v. 30, p. 1595-1599, 1987.

30. Smith, D.B. Droplet size and leaf morphology effects on pesticide spray deposition. Transactions of the ASAE.v.43, n.12, p.255$259,2000$.

31. Scudeler, F.; Bauer, F.C.; Raetano, C.G. Ângulo da barra e ponta de pulverização na deposição da pulverização em soja. In: Simpósio Internacional de Tecnologia de Aplicação de Agrotóxicos, 3. 2004, Botucatu, SP. Anais... Botucatu: FEPAF, 2004. p.1316.CD-Room

32. Souza, P. P. Evolução da cercosporiose e da mancha branca do milho e quantificação de perdas em diferentes genótipos, com controle químico. 2005. 77p. Dissertação (Mestrado em Fitopatologia) - ICIAG, UFU, Uberlândia. 